\title{
Mechanism of Action
}

National Cancer Institute

\section{Source}

National Cancer Institute. Mechanism of Action. NCI Thesaurus. Code C54680.

The mechanism by which a pharmacologically active substance produces an effect on a living organism or in a biochemical system. 